OPEN ACCESS

Edited by:

Aaron T. Scanlan,

Central Queensland University,

Australia

Reviewed by:

Marco Martin,

Sport Service Mapei Srl, Italy

Matteo Bonato,

University of Milan, Italy

Kenji Doma,

James Cook University, Australia

*Correspondence:

Toni Caparrós

toni.caparros@gencat.cat

Specialty section:

This article was submitted to

Movement Science and Sport

Psychology,

a section of the journal

Frontiers in Psychology

Received: 15 October 2021 Accepted: 20 December 2021 Published: 01 February 2022

Citation:

Caparrós T, Peña J, Baiget E, Borràs-Boix X, Calleja-Gonzalez $J$ and Rodas $G$ (2022) Influence of Strength

Programs on the Injury Rate and

Team Performance of a Professional Basketball Team: A Six-Season

Follow-Up Study.

Front. Psychol. 12:796098.

doi: 10.3389/fpsyg.2021.796098

\section{Influence of Strength Programs on the Injury Rate and Team Performance of a Professional Basketball Team: A Six-Season Follow-Up Study}

\author{
Toni Caparrós ${ }^{1,2 *}$, Javier Peña ${ }^{2,3}$, Ernest Baiget ${ }^{1,2}$, Xantal Borràs-Boix ${ }^{2,4}$, \\ Julio Calleja-Gonzalez ${ }^{5}$ and Gil Rodas ${ }^{6}$
}

${ }^{1}$ National Institute of Physical Education of Catalonia, University of Barcelona, Barcelona, Spain, ${ }^{2}$ Sport Performance Analysis Research Group (SPARG), University of Vic - Central University of Catalonia (UVic-UCC), Vic, Spain, ${ }^{3}$ Sport and Physical Activity Studies Centre (CEEAF), University of Vic - Central University of Catalonia (UVic-UCC), Vic, Spain, ${ }^{4}$ Universitat de Vic - Universitat Central de Catalunya, Barcelona, Spain, ${ }^{5}$ Physical Education and Sports Department, Faculty of Education and Sport, University of the Basque Country (UPV/EHU), Vitoria-Gasteiz, Spain, ${ }^{6}$ FC Barcelona Medical Services, Sant Joan Despí, Spain

This study aims to determine possible associations between strength parameters, injury rates, and performance outcomes over six seasons in professional basketball settings. Thirty-six male professional basketball players [mean \pm standard deviation (SD): age, $30.5 \pm 4.7$ years; height, $199.5 \pm 9.5 \mathrm{~cm}$; body mass, $97.9 \pm 12.9 \mathrm{~kg}$; BMl $24.6 \pm 2.5 \mathrm{~kg} / \mathrm{m}^{2}$ ] participated in this retrospective observational study, conducted from the 2008-09 to the 2013-14 season. According to their epidemiological records, each player followed an individual plan designed within different strength training programs: Functional $(n=16)$, Eccentric $(n=8)$, or Resistance $(n=12)$. Seven hundred and fourteen valid records were obtained from 170 individual strength tests during 31 sessions. Tests performed were leg press, squat, and jerk. Parameters recorded were force, power, velocity, peak velocity, and time to peak velocity for strength; time loss injury and muscle injury for injury rate; and games won, games lost, and championships for performance outcomes. All the strength variables and injuries are independent of the strength programs $(p<0.01)$. The correlation analysis showed very significant relationships between muscular injuries and time to peak velocity $(r=0.94 ; p<0.01)$, significant relationships between force and games lost $(r=0.85 ; p<0.05)$, and muscular injuries with games lost $(r=-0.81 ; p<0.05)$ per season. Mean values per season described a possible association of force, time to peak velocity, and muscular injuries with performance outcomes $\left(R^{2}=0.96 ; p<0.05\right)$. In this specific context, strength variables and injury rate data show no association with a single type of strength training program in this cohort of high-performance basketball players.

Keywords: individualization, periodization, load monitoring, force, time to peak velocity, muscle injuries 


\section{INTRODUCTION}

Basketball is a team sport with a complex nature (Mallo, 2020), and the competitive outcome is based on multiple performance factors. Therefore, it is almost impossible to know to what extent the physical, technical, tactical, or emotional aspects have contributed to athletic performance. Thus, numerous studies categorize relevant performance factors in the National Basketball Association (NBA) (Huyghe et al., 2021), the EuroLeague (Paulauskas et al., 2018), prestigious European championships, such as the Spanish "Liga ACB" (García et al., 2014), or even National Team competitions like the FIBA World Cup (Zhang et al., 2020), or the Olympic Games (Sampaio et al., 2010). However, these studies focused exclusively on analyzing the technical-tactical aspects, acknowledging that physical, physiological, or mental factors contribute to the player performance but without studying their specific impact on the game.

Other studies have adopted a different approach, monitoring, and assessing the impact of different training methods on basketball players' physical fitness, the impact of physical fitness on the execution of technical and tactical abilities, or the significance of injuries throughout a sports season at an individual and team level. For instance, Naclerio et al. (2013b) observed that high volume resistance training (three sets per exercise and nine sets per muscle group) was the best approach to increase strength in college team sport athletes with no previous resistance training experience during preseason, while low volume (one set per exercise and three sets per muscle group) seemed to be an interesting in-season strategy for maintaining strength and enhancing lower-body average power. The effects of these different programs were assessed via one repetition maximum (1 RM) and maximal average power (AP) on the bench press, upright row, and squat exercises using progressive tests. According to a study comparing professional and semiprofessional male basketball players, a standard preparation period (5-7 weeks, with athletes practicing 5-12 times a week, with 60-120 min practices) can induce improvements in professional players in abilities such as change of direction (COD). However, minimal differences between professional and semi-professional players were reported in the countermovement jump (CMJ) (Ferioli et al., 2018). On the other hand, a meta-analysis published in 2016 on strength training in healthy basketball players highlighted that interventions using external loads and even bodyweight exercises positively affected vertical jump ability (ES: 0.78 LARGE with 95\% CI: 0.41, 1.15) (Sperlich et al., 2016). The effect of different circuit-training protocols in vertical jump height and peak power, horizontal jump distance, 3-points percentage, bench-press power output, RSA total and ideal time, and agility $T$-Test in semiprofessional basketball players has also been analyzed (Freitas et al., 2016). The authors found no changes in performance in the group participating in power circuit training (45\% $1 \mathrm{RM})$, while the group using a high-resistance circuit training format (6 RM) presented decrements after 3 weeks. Plyometric training also seems a suitable training method to enhance muscle power, linear sprint speed, change-of-direction speed, balance, and muscle strength in basketball players, according to a recently published meta-analysis (Ramirez-Campillo et al., 2020). Similarly, Santos and Janeira (2012) demonstrated that a 10-week in-season resistance training program with moderate volume and intensity loads significantly increased vertical jump $(p<0.05)$ and medicine ball throw $(p<0.05)$ performances in the experimental group as compared to controls. Nevertheless, the study was conducted on twenty-five young male basketball players.

All the physical capacities improved by the strength and conditioning (S\&C) practices mentioned so far are relevant, as research shows a translation between fitness and technical performance. Analyzing this relationship is relevant in highly complex sports such as basketball if we want to understand the reasons why the improvement of physical abilities can to some extent be associated with optimal competitive performance. Thirty-eight first division players from Bosnia-Herzegovina showed an association via multiple regression between higher fatigue resistance and free throw performance, preplanned agility, countermovement jump, and fatigue resistance with the twopoint shot D2 $(R=0.44 ; p=0.03)$, and countermovement jump, medicine ball toss, and anaerobic endurance with the threepoint shot accuracy $(R=0.39 ; p=0.03)$ (Pojskic et al., 2018). However, we must clarify that the study evaluated technical performances outside of an actual competitive situation using static and dynamic shooting tests. According to a study with twenty-eight first division basketball players from Turkey, the type of training also seems a significant issue. The results showed that one of the study groups, under a functional training program (core strengthening and specific basketball task-related exercises with/without equipment) lasting 20 weeks with a frequency of two sessions per week, significantly improved upper and lower body strength, flexibility, vertical jump ability, and T-drill agility scores when compared to a control group following a more traditional strength training program consisting of freeweight and machine-based exercises (Usgu et al., 2020). The use of ecological tests to measure the benefits of the different training programs is also relevant since some articles highlight the absence of association between strength measures and results from field tests (Alemdaroglu, 2012). Regarding the use of different exercises, an interesting piece of research surveying soccer, basketball, handball, volleyball, indoor soccer, and field hockey elite Spanish teams (Reverter-Masía et al., 2009) observed that only handball and volleyball coaches used Olympic lifts consistently. Many single-joint exercises were used by indoor and outdoor soccer teams and, especially, basketball teams. Basketball and handball were the sports mainly using weighted squat jumps. Similarly, a study surveying 20 NBA S\&C coaches (69\% response rate) found that all the respondents used strategies to develop the range of motion, followed some periodization, with Olympic lifts being used by $95 \%$ of the coaches $(n=19)$, and reporting that the squat or its variations were used by many of the teams, and all of them employing plyometrics in their practices (Simenz et al., 2005). Therefore, research demonstrates that the variability of methods used in the physical training of team sports is substantial and relevant differences between scientific evidence and what professionals do in the "real world" also exist. 
Injuries in basketball are inevitable, as in any other discipline. Starkey reported that ankle sprains were the most frequent injury $(9.4 \%)$, followed by patellofemoral inflammation $(8.1 \%)$, lumbar strains $(5.0 \%)$, and knee sprains $(2.3 \%)$ in NBA players. Drakos et al. (2010), in a similar fashion, developed a 17-year longitudinal study in the same league, finding again that ankle sprains were the more recurrent medical issue $(13.7 \%$ of the cases observed), while patellofemoral inflammation was the leading cause of more missed games (17.5\%). According to the authors, professional NBA players undergo a high rate of game-related injuries. Contrarily, Rodas et al. (2019), in a study considering injury in an elite Spanish basketball club competing at the highest level of national and European leagues over nine seasons, found that muscle injuries (21.2\%) were more commonly observed compared with ankle sprains (11.9\%). Thus, prevention and therapeutic approaches to injuries in professional basketball settings are somewhat relevant.

Different authors have also analyzed the relationship between injuries, strength levels, workloads, and team-sport performance. Caparrós et al., 2014 found relations between squat strength (force), better performance (scored points) (rho $=-0.81$; $p<0.05)$, and fewer time-loss injuries (TLI) (rho $=0.82 ; p<0.05$ ) in a prospective study conducted on 12 Spanish professional male basketball players. Another study led by the same first author, but this time on NBA players, found that athletes under lower external loads were more prone to TLI (Caparrós et al., 2018). As some leagues present demanding competition schedules (McLean et al., 2018), the benefits of applied load management processes and different monitoring strategies seem relevant to protect professional players' physical integrity (Burgess, 2017). It is hypothesized that strength programs may reduce inter-limb asymmetries, a well-known internal risk factor for injuries (Bahr and Holme, 2003), limiting physical performance (Šarabon et al., 2020) and availability (Gabbett et al., 2018b).

Despite available research, to the best of our knowledge, there has been a limited attempt of examining the relationships between the use of different individualized strength training programs, injury rates, and competitive achievements in basketball longitudinally. This study aimed to determine possible associations between strength parameters, injury rates, and performance outcomes over six seasons in a European professional basketball team.

\section{MATERIALS AND METHODS}

\section{Study Design}

A retrospective observational study was carried out during six seasons in a professional basketball team (FC Barcelona) that played four main competitions every season. The data collection took place from 2008-09 to 2013-14, and players were allocated in three different strength training groups (functional, eccentric, or resistance training program) on each season, depending on their medical record. The measurements included individual strength assessments for each training group at the beginning and end of the mesocycles and team performance outcomes assessments per season. Baseline medical information was recorded from all participants at the beginning of each season through the FC Barcelona periodic health examination protocol. The protocol consisted of basic medical information (history), anthropometric data (age, height, weight, and ethnicity), physical examination, spirometry, basal 12-lead electrocardiography (ECG), submaximal cardiovascular exercise testing (with ECG and blood pressure monitoring), and cardiac echocardiography. Once a season started, various parameters potentially related to the type and frequency of musculoskeletal injuries (e.g., mechanism of injury) were collected. Athlete exposure and other variables, such as playing position, were recorded. We also collected clinical information and data related to the type of injury, TLI, medical attention (MA), and return to play (RTP) (Hägglund et al., 2005). Before implementing the strength training programs, all participants were required to perform familiarization tests and sessions. The S\&C coach recorded all strength and performance data (TC). The Team Physician (GR) was responsible for diagnosis and RTP decisionmaking for every injury and recorded all the injuries included in the current investigation. Data were recorded daily after every practice and game. All participants took part in another retrospective study previously published (Caparrós et al., 2016).

\section{Participants}

Thirty-six professional basketball players [mean \pm standard deviation (SD)]: age, $30.5 \pm 4.7$ years; height, $199.6 \pm 9.5 \mathrm{~cm}$; body mass, $97.9 \pm 12.9 \mathrm{~kg}$; BMI $24.6 \pm 2.5 \mathrm{~kg} / \mathrm{m}^{2}$ ) from a Spanish basketball club (FC Barcelona) participated in this study. Thirtytwo of them were Caucasian, and four were African American. Regarding their playing roles, 10 were guards, 11 were forwards, and 15 were centers. Two players played at the team during the six seasons of this follow up; 1 during 5 ; 5 players over 4 seasons; 4 over 3,11 over 2 , and 36 of them took part in at least 1 season $(1.7 \pm 1.2$ seasons per player) with a mean value of $13.0 \pm 0.9$ players per season. The inclusion criteria for all subjects required each participant to be part of the FC Barcelona professional team roster during a complete season and aged $>18$ years, not being involved in a TLI rehabilitation process, and not to change between training methods during the same season. During the study, 8 of the 44 starting participants were not able to meet the inclusion criteria. All the players and the club (FC Barcelona) were informed of the risks and benefits of the study and gave written informed consent to participate in this study. Players were allowed to decline the inclusion of their data. The study was conducted following the ethical principles for biomedical research with human beings, established in the Declaration of Helsinki of the World Medical Association (amended in 2013), and it was approved by the club Board of directors and the Research Ethics Committee of the University of Vic-Central University of Catalonia (favorable report available upon request).

\section{Strength Measurements}

Strength assessments were carried out at the beginning of the first mesocycle and at the end of each mesocycle to evaluate each period's initial and final state (Bangsbo et al., 2006). During the analyzed period, tests were conducted during the training sessions and were non-invasive (Bangsbo et al., 2006) using the 
main exercises of each program. They were performed during introductory microcycles (Naclerio et al., 2013b), and depending on the strength program and seasonal periodization, the test exercises were: single leg press (LP) (Cuadrado Sáenz et al., 2009) for the eccentric (ECC) and resistance (RES) programs and double-leg squat (SQ) (Caparrós et al., 2014) and jerk (JK) (Andújar Gutiérrez et al., 2015) for the functional (FUNC). Tests were carried out during the morning sessions after a full rest day, beginning with a warm-up consisting of $8 \mathrm{~min}$ of submaximal general physical activity, lumbopelvic analytic protocol, and joint mobility. Parameters recorded were force $(\mathrm{F})$, power $(\mathrm{P})$, velocity $(\mathrm{V})$, peak velocity $(\mathrm{pV})$, and time to peak velocity (tpV). They were evaluated indirectly through data gathered using a linear encoder with an accuracy $<0.075 \mathrm{~mm}$ (MuscleLab PFMA V.4000e, Ergotest Innovation AS, Norway) (Porta-Benache et al., 2010). Every player performed four series of each exercise with a progressive weight increase of $10 \mathrm{~kg}$ and a decreasing number of repetitions in each series $(12,10$, 8, and 6) (Naclerio et al., 2013a). Weights were individualized (Bangsbo et al., 2006) and could vary in each test (depending on the previous results and the periodized program), but there was always a minimum of two loads equal to the previous test, and the reference weight was the same throughout the whole season. The variables analyzed (F, P, V, pV, and tpV) in each exercise (LP, SQ, and JK) were determined to be reliable showing the following Guttman's Lamba 6 (G6) and coefficient of variation (CV) interval values at different weights: $115 \mathrm{~kg}$ [40-50\% of 1 repetition maximum (1 RM)]; for single LP (G6 $95 \%$ confidence interval $[\mathrm{CI}]=0.86-0.99 ; \mathrm{CV} 95 \% \mathrm{CI}=0.01-0.29), 90 \mathrm{~kg}(40-50 \%$ $1 \mathrm{RM})$ for SQ $(\mathrm{G} 695 \% \mathrm{CI}=0.94-0.99$; $\mathrm{CV} 95 \% \mathrm{CI}=0.01-0.24)$, and $35 \mathrm{~kg}(40-50 \% 1 \mathrm{RM})$ for JK (G6 95\% CI $=0.81-0.94$; CV $95 \% \mathrm{CI}=0.05-0.26)$.

All the players underwent assessments as part of their training routine, and therefore the possibility of a player being injured because of the participation in the study was not considered. The S\&C coach carried out the assessments, and all the players were familiar with the technique and protocol. To ensure that the testing was carried out consistently, the acoustic feedback provided by the encoder software was enabled during the execution of the tests. It was used to determine the minimum individual power level to be achieved.

\section{Injury Measurements}

To monitor injuries, we followed the model proposed by Hägglund et al. (2005), as well as the premises of Fuller et al. (2006). The study focused on TLI that caused absence from practices, workouts, or games, and among these, the group of muscular injuries (MI)-rupture, tear, strain, cramps or tendon ruptures, tendinosis or bursitis-were followed up.

\section{Performance Outcomes Measurements}

Five Team performance outcomes were considered: the Spanish Super Cup, the King's Cup, the Euroleague Final Four qualification stage, the Euroleague Final Four, and the Spanish League (ACB). Games won (GW), games lost (GL), and championships won (CW) were recorded on each season (Caparrós et al., 2016).

\section{Periodization}

To achieve the competitive goals, every season was divided into seven mesocycles, always considering the competition calendar. The first performance outcome fell within mesocycle 1 (Spanish Super Cup). Mesocycle 2 focused on the start of the regular season of the Spanish League (ACB) and the Euroleague season. Most of the first phase of the regular competitions takes place during Mesocycle 3. Mesocycle 4 included the second performance outcome (King's Cup). Mesocycle 5 covered the second phase of the regular competitions and the Euroleague playoffs (third outcome). Mesocycle 6 ended with the Euroleague Final Four (fourth outcome), and Mesocycle 7 comprised ACB playoffs for the championship as the fifth performance outcome (see Figure 1).

The duration of each season was $43 \pm 2$ weeks. Workload planning, both conditional and technical/tactical, was designed with as similar a structure as possible between mesocycles, with a duration of $6 \pm 1$ weeks. Mesocycle periodization followed the blocked periodization model (Issurin, 2008), and the progression of contents was divided into four orientations (general, directed, specific, and competitive) (Schelling and Torres-Ronda, 2013).

The design of the mesocycles was adapted to the game days, two per week during the regular season phases (31 weeks), except $5 \pm 2$ weeks with a single game. During the ACB and Euroleague playoffs, and in the King's Cup (8 weeks), three games were played weekly. The usual structure of each of the microcycles in each mesocycle was as follows: 1 day or morning session free with a recovery session in the afternoon; Monday and Tuesday: double session with strength and individual strength workouts in the morning and tactical session in the afternoon; Wednesday: tactical session in the afternoon; Thursday: pregame session in the morning and game in the afternoon; Friday afternoon: recovery and joint technical/tactical session; Saturday morning: tactical session; and Sunday: game (with a pre-game session if it was in the afternoon) (see Figure 2). In addition, each player had an individualized preventive program, a strength workout, or practice to be performed before joint practices or during free days. Players with a lower competitive load had a compensatory practice on Monday morning (Gabbett, 2016; Caparrós et al., 2018).

\section{Strength Programs}

An integrative strength training program was designed for each player (Schelling and Torres-Ronda, 2016). In the light of their medical history, the players were distributed into three distinct workgroups. Those with the fewest constraints participated in the FUNC program (Schelling and Torres-Ronda, 2016), consisting of a multi-joint exercise routine, easily transferable to competitive play (Pojskic et al., 2018). These routines were performed with free weights, bodyweight exercises, medicine, weight balls, resistance bands, and mini bands. Those players whose injury records showed a history of tendon or muscle injuries were placed in the ECC program, which included both multi-joint and analytic exercises and was eminently preventive, emphasizing the eccentric component of the exercises 


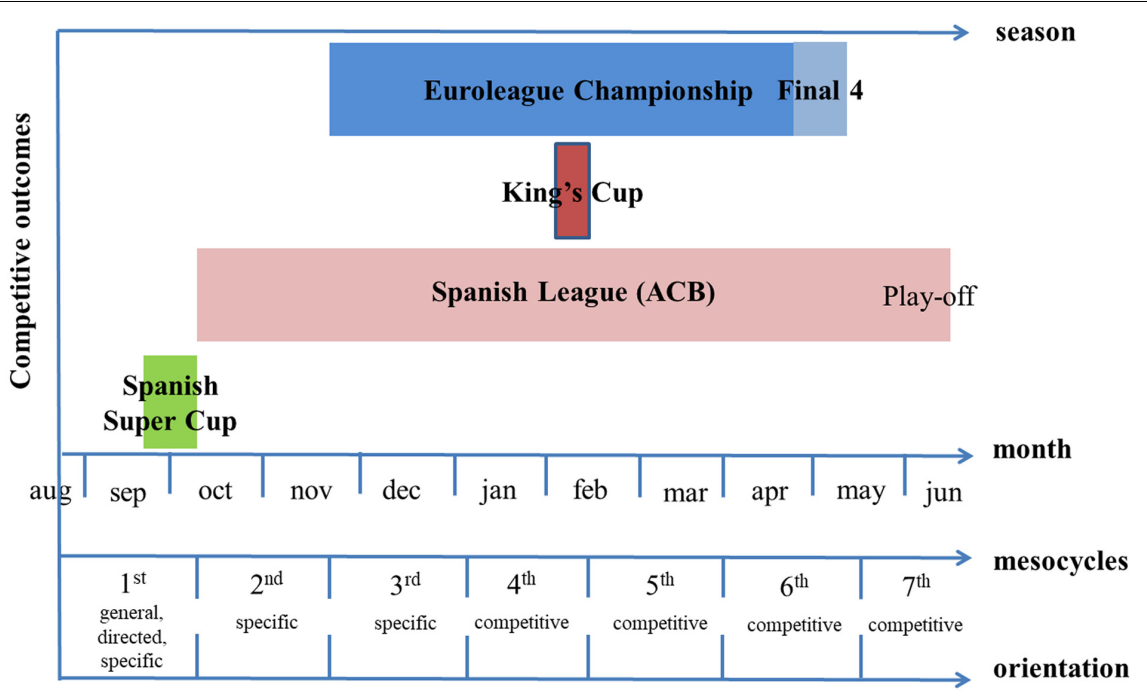

FIGURE 1 | Timeline of season competitive outcomes, mesocycles, and mesocycle orientation.

\begin{tabular}{|c|c|c|c|c|c|c|c|}
\hline \multicolumn{8}{|c|}{ Miscopde period iration model } \\
\hline & Monday & Tuesday & Wednesday & Thursday & Friday & Saturday & Sunday \\
\hline 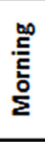 & off & $\begin{array}{l}\text { Conditioning: } \\
\quad 45 \text { min } \\
\text { Strength }{ }^{*}+30 \\
\text { min specific }\end{array}$ & off & $\begin{array}{l}\text { Technical Pre- } \\
\text { Game } 60 \text { min }\end{array}$ & off & Tactical $90 \mathrm{~min}$ & $\begin{array}{l}\text { Technical Pre- } \\
\text { Game } 60 \mathrm{~min}\end{array}$ \\
\hline 동 & off & Tactical $90 \mathrm{~min}$ & Tactical $90 \mathrm{~min}$ & GAME & $\begin{array}{c}\text { Recovery } \\
\text { practice: } 30 \\
\text { min Strength + } \\
45 \text { min }\end{array}$ & off & GAME \\
\hline
\end{tabular}

FIGURE 2 | Microcycle periodization model; * test sessions.

(Roig Pull and Ranson, 2007; Peña et al., 2017). The tools used for this program were strength machines, own bodyweight, medicine ball and weight balls, and resistance bands and mini bands. Finally, those who had chronic joint injuries or were older were assigned to the Resistance (RES) program, oriented to specific muscle groups (Naclerio et al., 2013b). Tools used for this program were weight machines, own body weight, and resistance bands and mini bands. Subsequently, depending on their age and playing characteristics, the exercise program, progression, and workload were adapted individually. The program's degree of specificity (Wen et al., 2018) and the volume and intensity of work were determined by the time of the season and by the orientation of the previous mesocycles. Therefore, strength work was integrated with the team's technical and tactical needs according to the competition calendar (McLean et al., 2018; see Figure 3).

\section{Statistical Methods}

Data are presented as mean \pm standard deviation (SD). After performing a central tendency descriptive study and considering the non-normality of the sample, the Kruskal-Wallis test was used to evaluate the effects of the strength training program (independent variables) on dependent variables (strength and injury rate parameters). For this purpose, we used the values $(\mathrm{F}, \mathrm{P}, \mathrm{V}, \mathrm{pV}$, and $\mathrm{tpV}$ ) of the best repetition in each series of each test (LP, SQ, and JK) recorded. A Dunn-Bonferroni post hoc test was performed in turn. Intrasession reliability of measures was determined using the Guttman's Lambda 6 test with 95\% confidence intervals (Oosterwijk et al., 2016). The results were weighted to take account of the number of players in each program. Subsequently, and considering the normality of the average values by season, it was performed Pearson's rho correlation analysis between the variables of the best repetition in each test for the strength, injury, and performance outcome variables. The correlation magnitude was defined according to Hopkins's criteria (Hopkins, 2002): random: 0-0.09; low: 0.100.29 ; moderate: $0.30-0.49$; large: $0.50-0.69$; very large: $0.70-$ 0.89 ; nearly perfect $0.90-0.99$; perfect: 1 . Finally, the multiple linear regression analysis used performance outcomes as the dependent variable, whereas strength and injury rate parameters operated as independent predictors. The statistical analyses were performed with JASP software version 0.11.1 (The Jasp Team, Amsterdam, Holland). The level of significance was set at $p<0.05$. 


\begin{tabular}{|c|c|c|c|c|c|c|}
\hline Method & \multicolumn{4}{|c|}{ Mesocycle Orientation } & \multicolumn{2}{|c|}{ Progression } \\
\hline \multirow{17}{*}{ Functional } & General & Directed & Specific & Competitive & Sets & Repetitions \\
\hline & Squat $^{*}$ & Squat* & & & 3 or 4 & 6 to 12 \\
\hline & & & Clean \& Jerk & Clean \& Jerk & 3 or 4 & 6 to 12 \\
\hline & & Clean & Clean & Clean & 3 or 4 & 6 to 12 \\
\hline & & & Jerk* & Jerk* & 2 or 3 & 6 to 10 \\
\hline & Step up & Step up & Step up & Step up & 2 or 3 & 6 to 12 \\
\hline & & Lateral step & Lateral step & Lateral step & 3 or 4 & 6 to 12 \\
\hline & Bench press & Bench press & Bench press & Bench press & 2 or 3 & 8 to 12 \\
\hline & Cable row & Cable row & Cable row & Cable row & 2 or 3 & 6 to 15 \\
\hline & Gluteus bridge & Gluteus bridge & Gluteus bridge & Gluteus bridge & 2 to 4 & 10 to 15 \\
\hline & Landmine Press & Landmine Press & Landmine Press & Landmine Press & 3 or 4 & 6 to 12 \\
\hline & & Monster walks & Monster walks & Monster walks & 3 or 4 & 8 to 15 \\
\hline & Core workout & Core workout & Core workout & Core workout & 3 or 4 & $10 \mathrm{~s}$ to $20 \mathrm{~s}$ \\
\hline & & Push ups & Push ups & Push ups & 1 to 3 & 6 to 10 \\
\hline & & Pull ups & Pull ups & Pull ups & 2 to 4 & 4 to 8 \\
\hline & & & Front jumps & Front jumps & 2 to 4 & 4 to 8 \\
\hline & & & Lateral jumps & Lateral jumps & 2 to 4 & 4 to 8 \\
\hline \multirow{16}{*}{ Eccentric } & Leg Press* & & & & 3 or 4 & 6 to 12 \\
\hline & Russian belt & Russian belt & Russian belt & & 3 or 4 & 6 to 12 \\
\hline & & Back lunge & Back lunge & Back lunge & 3 or 4 & 6 to 12 \\
\hline & Adductor Slider & Adductor Slider & Adductor Slider & Adductor Slider & 2 or 3 & 6 to 10 \\
\hline & Hamstrings & Hamstrings & Hamstrings & Hamstrings & 2 or 3 & 6 to 12 \\
\hline & Gluteus & Gluteus & Gluteus & Gluteus & 3 or 4 & 6 to 12 \\
\hline & Soleus & Soleus & Soleus & Soleus & 2 or 3 & 8 to 12 \\
\hline & Bench press & Bench press & Bench press & Bench press & 2 or 3 & 6 to 15 \\
\hline & Cable row & Cable row & Cable row & Cable row & 2 to 4 & 10 to 15 \\
\hline & Landmine Press & Landmine Press & Landmine Press & Landmine Press & 3 or 4 & 6 to 12 \\
\hline & Core workout & Core workout & Core workout & Core workout & 3 or 4 & $10 \mathrm{~s}$ to $20 \mathrm{~s}$ \\
\hline & & Push ups & Push ups & Push ups & 3 or 4 & 10 to 15 \\
\hline & & Pull ups & Pull ups & Pull ups & 1 to 3 & 6 to 10 \\
\hline & & Step Down & Step Down & Step Down & 2 to 4 & 4 to 8 \\
\hline & & & Front jumps & Front jumps & 2 to 4 & 4 to 8 \\
\hline & & & Lateral jumps & Lateral jumps & 2 to 4 & 4 to 8 \\
\hline \multirow{11}{*}{ Resistance } & \multicolumn{4}{|c|}{ Leg Press* } & 2 to 4 & 6 to 12 \\
\hline & \multicolumn{4}{|c|}{ Adductor (slidding or assisted by S\&C Coach) } & 2 or 3 & 6 to 10 \\
\hline & \multicolumn{4}{|c|}{ Hamstrings (Ecc phase Leg Curl or assited by S\&C coach) } & 2 or 3 & 6 to 12 \\
\hline & \multicolumn{4}{|c|}{ Gluteus } & 3 or 4 & 6 to 12 \\
\hline & \multicolumn{4}{|c|}{ Soleus } & 2 or 3 & 8 to 12 \\
\hline & \multicolumn{4}{|c|}{ Bench press } & 3 or 4 & 10 to 15 \\
\hline & \multicolumn{4}{|c|}{ Dorsal Cable row } & 3 or 4 & 10 to 15 \\
\hline & \multicolumn{4}{|c|}{ Lateral shoulder raises } & 3 or 4 & 6 to 10 \\
\hline & \multicolumn{4}{|c|}{ Core workout } & 1 to 3 & $10 \mathrm{~s}$ to $20 \mathrm{~s}$ \\
\hline & \multicolumn{4}{|c|}{ Push ups } & 2 to 4 & 10 to 15 \\
\hline & \multicolumn{4}{|c|}{ Pull ups } & 2 to 4 & 6 to 10 \\
\hline
\end{tabular}

FIGURE 3 | Main strength exercises and progression by method and mesocycle orientation; *test exercises.

\section{RESULTS}

The 36 players were distributed between the strength training programs: RES: 12; ECC: 8 ; FUNC: 16. Seven hundred fourteen test valid records were obtained ( $27.5 \pm 3.5$ per player), of which 111 were from the RES group, 132 from ECC, and 471 from FUNC. The records were made during 170 individual tests in 31 sessions $(5.2 \pm 1.9)$ days of tests per season and $(4.9 \pm 2.2)$ tests performed per player. Of these tests, 26 were LP for the RES group, 12 were LP for ECC, 108 were SQ for FUNC, and 24 were JK for FUNC. There was a relevant difference between the numbers of test records in different seasons. The average was 119 records per year, going from a maximum of 228 in the second season (2009-10) to a gradual decline, reaching 29 in the last season (2013-14).

\section{Strength Programs}

Regarding the strength values recorded for each program, RES showed the highest $\mathrm{F}(1196.1 \pm 356.8 \mathrm{~N})$ compared to the FUNC with the lowest values $(964.3 \pm 266.2 \mathrm{~N})$. FUNC showed the highest values for $\mathrm{P}(842.5 \pm 183.1 \mathrm{~W}), \mathrm{V}(0.92 \pm 0.29 \mathrm{~m} / \mathrm{s})$, and $\mathrm{pV}(1.39 \pm 0.58 \mathrm{~m} / \mathrm{s})$, and a lower tpV $(0.25 \pm 0.08 \mathrm{~s})$. RES showed the worst values in all these cases, except in tpV, where it was ECC (see Figure 4). 

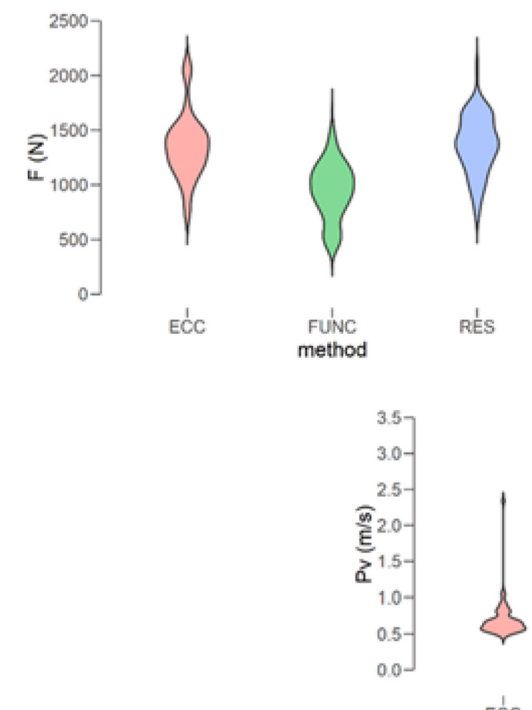

ECC
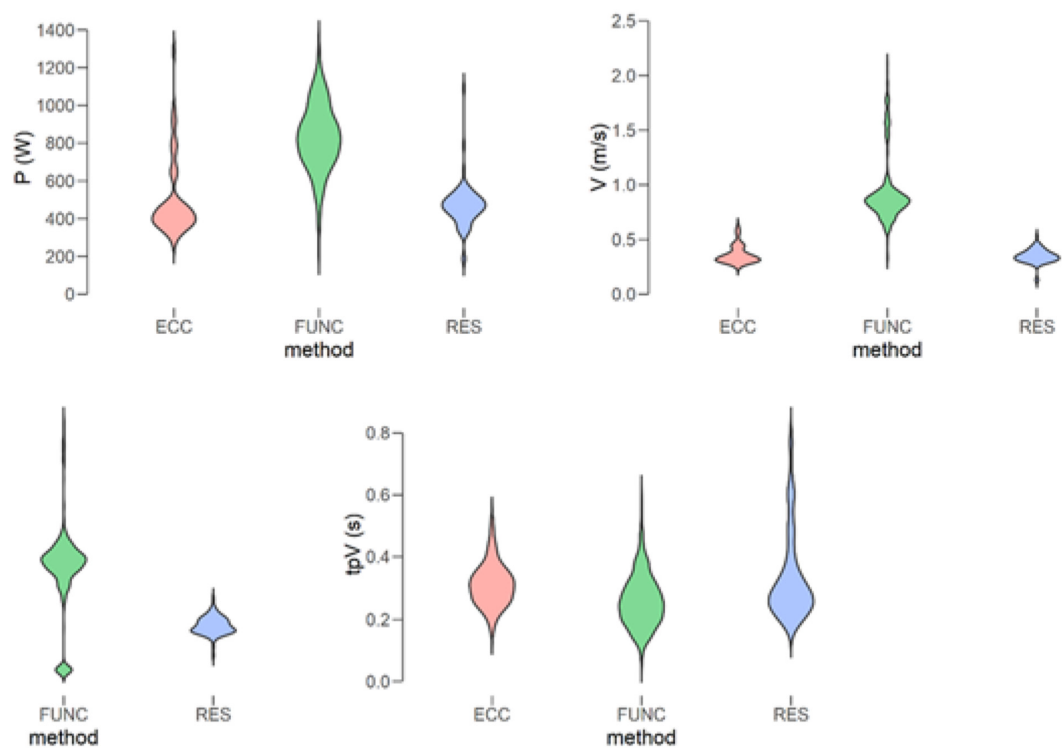

FIGURE 4 | Absolute values of Force $(F)$, Power $(P)$, Velocity $(\mathrm{M}$ ), peak Velocity $(\mathrm{pV})$, and time to peak Velocity (tpV) by strength training method (Eccentric-ECC-Functional-FUNC-or Resistance-RES). N, newtons; W, watts; m/s, meters per second; s, seconds.

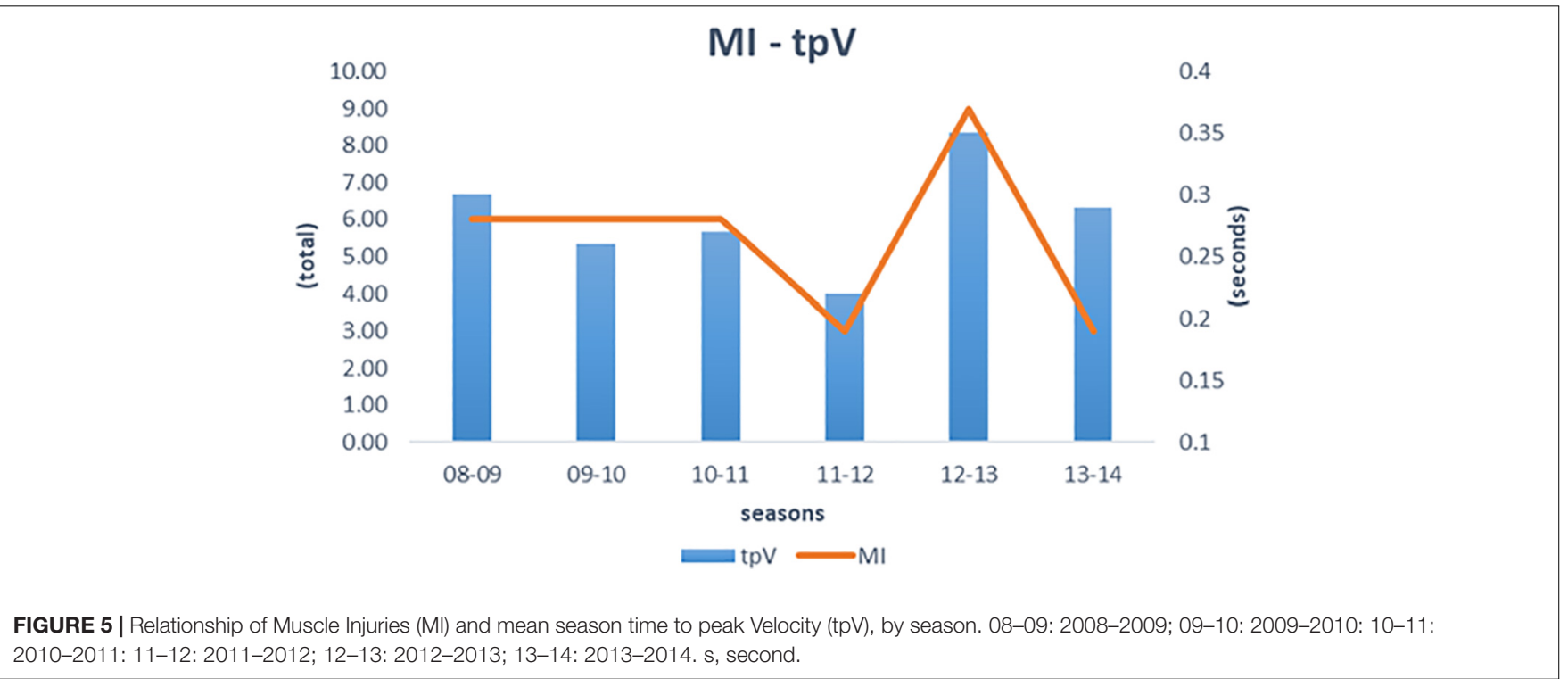

Statistically, the Kruskal-Wallis test enabled us to determine the independence $(H=43.69-146.61 ; d f=2 ; p<0.001)$ of all the strength variables $(\mathrm{F}, \mathrm{P}, \mathrm{V}, \mathrm{pV}$, and tpV) according to the test performed and considering all the strength programs. The post hoc test, in turn, also determined that these differences were present between each of the variables in every training group (z: -10.37 to 7.41 ; wi: $197.77-467.29$; wj: 256.26-467.09; $\left.p_{\text {Bonf }}<0.05\right)$.

\section{Injuries}

A total of 149 TLI were recorded during the six seasons, with averages of $24.7 \pm 7.6$ TLI and $6.0 \pm 1.9$ MI per season. An incidence of 37 TLI in the 2012-13 season stands out as the highest value, with a maximum of $9 \mathrm{MI}$, in contrast to the 201112 season with 17 TLI, only 3 were MI. In terms of mesocycles, the third produced the highest number of injuries (58), followed by the second (24), fourth (14), fifth (13), seventh (11), first (10), and sixth (6).

No significant differences were observed in the number of injuries according to the training group, so they should not be determined by this factor. Differences did emerge between seasons $(H=36.21 ; d f=5 ; p<0.001)$ and mesocycles $(H=65.01$; $d f=6 ; p<0.001)$. The post hoc test highlighted differences between the 2012-13 with the rest of the seasons ( $\mathrm{z}:-4.57$ to $4.13 ; \mathrm{w}_{\mathrm{i}}: 315.62-385.65 ; \mathrm{w}_{\mathrm{j}}: 315.62-432.3 ; p_{\text {Bonf }}<0.01$ ) (see Figure 5). Regarding the mesocycles, the same test showed 
differences between the third and the other six ( $\mathrm{z}$ : -6.4 to 6.05 ; $\left.\mathrm{w}_{\mathrm{i}}: 322.86-439.54 ; \mathrm{w}_{\mathrm{j}}: 322.58-434.54 ; p_{\text {Bonf }}<0.001\right)$.

\section{Team Performance Outcomes}

A total of 425 games were played, of which 342 were won (80.5\%) and 83 lost (19.5\%), with an average of $57.0 \pm 4.3$ games won (GW) per season, reaching a peak of 63 in the 2013-14 season, and $13.8 \pm 4.6$ games lost (GL) per season, the highest value was 21 in 2012-13. In all, 16 competitive objectives were attained, an average of $2.7 \pm 0.9$ per season, outstanding among which were the four performance outcomes in 2009-10 (Super Cup, King's Cup, Final Four qualification, and Euroleague Championship). Three were achieved during the 2010-11 and 2011-12 seasons, and two in the other seasons.

\section{Relationships Among Variables}

The correlation analysis using Pearson's rho test showed very significant (nearly perfect) relationships between MI and tpV (r: $0.94 ; p<0.01)$ (see Figure 5) and significant (very large) relationships between $\mathrm{F}$ and GL per season (r: $0.85 ; p<0.05)$ and also between MI and GL per season ( $\mathrm{r}:-0.81 ; p<0.05)$.

A multiple linear regression analysis was used to select the most promising independent variables (strength and injury rate parameters) to determine performance outcomes. The procedure revealed that $\mathrm{F}, \mathrm{tpV}$, and $\mathrm{MI}$ parameters together accounted for $92 \%$ of the variation of performance outcomes over the six seasons $\left(r=0.98, r^{2}=0.97\right.$, adjusted $\left.r^{2}=0.92, p<0.01\right)$.

\section{DISCUSSION}

The present longitudinal study aimed to analyze potential associations among three strength training programs, team performance, and injury rates during six seasons in a top basketball professional team that included thirty-six male players. Among others, the most critical findings in this specific context are that strength variables and injury rate are independent of the training program. Finally, strength variables such as $\mathrm{F}, \mathrm{tpV}$, and MI could be associated with team performance outcomes. However, the team periodization might be designed and interpreted according to the individual players' needs, competitive schedule, and team goals of each different season.

The competition calendar determines team periodization (Ireland et al., 2019), with a very high traveling frequency required to compete in elite professional sport (Calleja-Gonzalez et al., 2020). In this scenario, the design of both strength programs and their workload should be adapted to each player's individual needs and characteristics (Rogalski et al., 2013). Concretely, during the six seasons analyzed, the players studied were distributed in three types of strength programs precisely based on their individual profiles (Gabbett et al., 2014). No differences emerged among the recorded variables, either of strength or susceptibility to injury, allowing to assess this distribution positively and design tailored to each player (Bogdanis et al., 2007). For this purpose, it is necessary to monitor, as far as possible, and in a specific and non-invasive manner (Bangsbo et al., 2006), all the available performance, physical fitness, and health parameters from a holistic approach (Nagorsky and Wiemeyer, 2021). Using a comprehensive framework for sports training with a performance model integrating insights from game research and sport science (Calleja-González et al., 2018) the aim is to be fully available for competitive play (Gabbett et al., 2018b). Monitoring of load management allows to adapt individual programs (Fernández et al., 2021), to competition demands, but involving players and staff in common team objectives (Thorpe et al., 2017) and combine competition demands and each member of staff (Gabbett et al., 2018a).

Overall, all the strength variables analyzed behaved independently of each other. Periodization was different every season, given that although the coach and staff were the same, the entire roster was not. In turn, the programming and load design were adapted to the determinants of a highly competitive context: changing squad, with some older players; more games for a new Euroleague schedule from the 2011-2012 season; and an increasing pressure to maintain the team performance outcomes success. The data can be well-contextualized in the team's current competitive situation, allowing each season and programming unit to be interpreted independently. Periodization will depend on multiple factors (Aoki et al., 2017), and each season must be analyzed and all the contents tailored to specific needs (Stone and Steingard, 1993).

From the 2011-12 season onward, the number of games in European competition increased, and this meant going from having between 12 and 14 weeks with a single game to at most 4 . At that point, conditioning had to be oriented more to recovery than to accumulation (Fox et al., 2018) managing strength work now focused on intensity rather than volume (Naclerio et al., 2013b). Up till then, the first day of the week in the gym was performed with general or directed contents, and second for more specific ones. But from then on, the second weekly session was predominantly for recovery (Calleja-González et al., 2016), so the first had to include more specific contents during the period of competition (Fox et al., 2020), with the aim to perform higher P, V, and pV values (Santos and Janeira, 2012). The fact is that the new calendar entailed a reduction in the accumulation period, additionally to the constraint of competing for the first competitive goal at the end of the preseason (Doeven et al., 2020). In this sense, the F levels could not be adopted as before, representing a physical limitation (Šarabon et al., 2020). Greater specificity may conditionally be assumed (Fernandesda-Silva et al., 2016), but it can be related to other issues such as performance (Gabbett et al., 2018a) and susceptibility to injury (Hulin et al., 2016). Each phase of the season presents different demands (Ferioli et al., 2018): the first phase of three mesocycles was oriented toward $\mathrm{F}$ work, with the subsequent management of $\mathrm{P}$ and qualitative and specific issues at the end of the season (Ferioli et al., 2021). This could be related to susceptibility to injury and observed during the third mesocycle (accumulating as many as 37 injuries), a period that coincides with an overload of competition and training, as well as periods of acute overload (spikes) (Hulin et al., 2014) at a conditional level. Correct data interpretation would lead to moderate this workload in this mesocycle to aid recovery (Terrados et al., 2019). For this purpose, the preceding mesocycles are essential 
in the appropriate management of chronic workload (Gabbett, 2016), and monitoring weekly changes during the in-season phase should help to adjust acute workload that may predispose players to unwanted spikes (Paulauskas et al., 2019).

In a previous study with this sample (Caparrós et al., 2016), TLI was not related to the competitive outcome. However, in this case, the correlation analysis, now including conditional factors, does identify clear relationships between MI and F and GL in the season $(p<0.05)$ - which in turn are related to the achievement of championships as team performance outcomes $(p<0.05)$. The fact is that during the first three seasons, the development of $\mathrm{F}$ in the first mesocycles made it possible to take on conditional levels that enabled players to reach a competitive fitness state (Speranza et al., 2015) and with the squad members available in all competitions. Nevertheless, during the last three seasons (from 2011 to 2012), the exercises' orientation was more specific on a more congested calendar. Subsequently, these are associated with greater susceptibility to injury in this specific context, especially muscle injury, which would be closely related to lower $\mathrm{F}$ values (Malone et al., 2019) or worse recovery, reflected in variables of a qualitative nature that deteriorate, such as pV (Serpiello et al., 2011). These factors are associated with shorter preseasons (Killen et al., 2010) and a fuller competitive calendar, noting two different trends: first, there is the highest injury incidence during the third mesocycle. Players could have reached this point in a competitive state of fitness but with less capacity for recovery from these exertions at this point of the season (Killen et al., 2010). And second, lower injury rates are on seasons with best tpV values. Load management must balance recovery strategies and optimal strength training, avoiding low chronic workloads (Malone et al., 2019) too early in the season.

It is essential to note the association among $\mathrm{F}, \mathrm{tpV}$, and MI $\left(R^{2}=0.96\right)$, but it needs to be put into context. The proposed model establishes that in this specific context, the three variables determine performance outcomes. The optimal chronic strength values (Caparrós et al., 2014) and the specific details of the proposal need to be determined for each player (Ferioli et al., 2021). The tpV value and its possible relationship to muscle recovery (Serpiello et al., 2011) and better states of fitness (Fernandes-da-Silva et al., 2016) must be adequately monitored throughout the in-season (Gabbett, 2016; Paulauskas et al., 2019). These two factors, in turn, could determine muscle injury. Injuries may continue not to impede competing in championships. However, correct management and monitoring of variables such as $\mathrm{F}$ and $\mathrm{tpV}$, and consequently a reduction in muscle injuries (Rodas et al., 2019), will make it possible to have a roster in its full potential to achieve the maximum number of competitive goals, as happened in the seasons from 2009-10 to 2011-12.

The present study presents limitations inherent in a sporting and competitive context, despite the wealth of data related to the study period, players in the sample, and team performance outcomes. First, and from a global vision, the possibility of comparing this longitudinal study with others would allow us to determine the applicability of the results. Second, and for this specific case, having different tests does not allow us to obtain consistent results, but that was not the intention in this research. Each workgroup and player must be assessed independently to adopt the same objectives simultaneously as a team. In this connection, given these specific sporting processes, not all the players were monitored using all the tests; in some cases, they were injured. Third, and related to the number of tests, a gradual decrease occurred as the seasons passed. Nevertheless, primarily, the reduction in the quality of monitoring must be assessed and, once again, interpreted: the increase in the number of games reduced the number of sessions that included exercises for recording data. And especially in the last two seasons, although competitive objectives were undertaken, the number of games lost was higher, and consequently, competitive pressure did not make it easy for the staff to manage data collection. Neither the seasons' routine nor adverse competitive situations should give rise to a lack of rigor in any detail of the training process. These are precisely the situations in which greater importance should be given to monitoring (Burgess, 2017), to optimize the players' performance as much as possible, monitoring the attainment of the objectives of periodization, and not overlooking risk factors (Gabbett et al., 2018a). However, the strength of this study is a six-season follow-up of top Euroleague players, to date not described, in the daily reality of the sports competition.

To conclude, in this specific context, strength variables and injury rate data show no association with a single type of strength training program in this cohort of high-performance basketball players. F, tpV, and MI showed association with team performance outcomes.

\section{PRACTICAL APPLICATIONS}

Performance (both team and individual) data and strength variables should be integrated in the workload monitoring process, with the aim to optimize training, individual availability for competition, and team performance outcomes. This process is longitudinal, and it is the staff's responsibility to involve the players in it to understand their importance for improving their performance and health. Sports organizations and coaches should assess these data using this perspective. In turn, S\&C and Sports Science professionals have more tools and experience available to manage this process in an ethical and minimally invasive manner, providing the rest of the staff and the players with concise and reliable information.

\section{DATA AVAILABILITY STATEMENT}

The raw data supporting the conclusions of this article will be made available by the authors, without undue reservation.

\section{ETHICS STATEMENT}

The studies involving human participants were reviewed and approved by the Universitat de Vic-Universitat Central de Catalunya Research Ethics Committee. The participants provided their written informed consent to participate in this study. 


\section{AUTHOR CONTRIBUTIONS}

TC and GR conceived and designed the research, analyzed and interpreted the data, drafted the article, and approved the final version submitted for publication. JP and EB

\section{REFERENCES}

Alemdaroglu, U. (2012). The relationship between muscle strength, anaerobic performance, agility, sprint ability and vertical jump performance in professional basketball players. J. Hum. Kinet. 31, 149-158. doi: 10.2478/ v10078-012-0016-6

Andújar Gutiérrez, J. J., López del Amo, J. L., and Marina Evrard, M. (2015). Caracterización del tiempo de vuelo en relación con variables biomecánicas del tirón en la arrancada de halterofilia. Apunts Educación Física y Deportes 118, 68-78. doi: 10.5672/apunts.2014-0983.es.(2014/4).118.07

Aoki, M. S., Ronda, L. T., Marcelino, P. R., Drago, G., Carling, C., Bradley, P. S., et al. (2017). Monitoring training loads in professional basketball players engaged in a periodized training program. J. Strength Cond. Res. 31, 348-358. doi: 10.1519/JSC.0000000000001507

Bahr, R., and Holme, I. (2003). Risk factors for sports injuries-a methodological approach. Br. J. Sports Med. 37, 384-392. doi: 10.1136/bjsm.37.5.384

Bangsbo, J., Mohr, M., Poulsen, A., Perez-Gomez, J., and Krustrup, P. (2006). Testing and training the elite athlete. J. Exerc. Sci. Fit. 4, 1-14.

Bogdanis, G. C., Ziagos, V., Anastasiadis, M., and Maridaki, M. (2007). Effects of two different short-term training programs on the physical and technical abilities of adolescent basketball players. J. Sci. Med. Sport 10, 79-88. doi: 10.1016/j.jsams.2006.05.007

Burgess, D. J. (2017). The research doesn't always apply: practical solutions to evidence-based training-load monitoring in elite team sports. Int. J. Sports Physiol. Perform. 12, 136-141. doi: 10.1123/ijspp.2016-0608

Calleja-Gonzalez, J., Marques-Jimenez, D., Jones, M., Huyghe, T., Navarro, F., Delextrat, A., et al. (2020). What are we doing wrong when athletes report higher levels of fatigue from traveling than from training or competition? Front. Psychol. 11:194. doi: 10.3389/fpsyg.2020.00194

Calleja-González, J., Mielgo-Ayuso, J., Sampaio, J., Delextrat, A., Ostojic, S. M., Marques-Jiménez, D., et al. (2018). Brief ideas about evidence-based recovery in team sports. J. Exerc. Rehabil. 14, 545-550. doi: 10.12965/jer.1836244.122

Calleja-González, J., Terrados, N., Mielgo-Ayuso, J., Delextrat, A., Jukic, I., Vaquera, A., et al. (2016). Evidence-based post-exercise recovery strategies in basketball. Phys. Sportsmed. 44, 74-78. doi: 10.1080/00913847.2016.1102033

Caparrós, T., Alentorn-Geli, E., Myer, G. D., Capdevila, L., Samuelsson, K., Hamilton, B., et al. (2016). The relationship of practice exposure and injury rate on game performance and season success in professional male basketball. J. Sports Sci. Med. 15, 397-402.

Caparrós, T., Casals, M., Solana, Á, and Peña, J. (2018). Low external workloads are related to higher injury risk in professional male basketball games. J. Sports Sci. Med. 17, 289-297.

Caparrós, T., Padullés Riu, J. M., Rodas Font, G., and Capdevila, L. (2014). La força pot predir el rendiment i la lesionabilitat al bàsquet professional? Apunts Educació Física i Esports 100, 48-58.

Cuadrado Sáenz, G., Benito Trigueros, A., Sedano Campo, S., Izquierdo Velasco, J., Redondo Castán, J., and Granado, J. (2009). Efectos de un programa de entrenamiento de la fuerza-resistencia sobre los niveles de resistencia. Eur. J. Hum. Mov. 22, 47-64. doi: 10.21134/eurjhm.2009.22.218

Doeven, S. H., Brink, M. S., Huijgen, B. C. H., de Jong, J., and Lemmink, K. A. P. M. (2020). Managing load to optimize well-being and recovery during short-term match congestion in elite basketball. Int. J. Sports Physiol. Perform. 16, 45-50. doi: 10.1123/ijspp.2019-0916

Drakos, M. C., Domb, B., Starkey, C., Callahan, L., and Allen, A. A. (2010). Injury in the national basketball association: a 17-year overview. Sports Health 2, 284-290. doi: 10.1177/1941738109357303

Ferioli, D., Bosio, A., Bilsborough, J. C., Torre, A., Tornaghi, M., and Rampinini, E. (2018). The preparation period in basketball: training load and neuromuscular adaptations. Int. J. Sports Physiol. Perform. 13, 991-999. doi: 10.1123/ijspp. 2017-0434 analyzed and interpreted the data, and drafted the article. $\mathrm{JP}, \mathrm{EB}, \mathrm{XB}$, and JC-G critically reviewed the article and approved the final version submitted for publication. All authors contributed to the article and approved the submitted version.

Ferioli, D., Scanlan, A. T., Conte, D., Tibiletti, E., and Rampinini, E. (2021). The business end of the season: a comparison between playoff and regular-season workloads in professional basketball players. Int. J. Sports Physiol. Perform. 16, 655-662. doi: 10.1123/ijspp.2020-0405

Fernandes-da-Silva, J., Castagna, C., Teixeira, A. S., Carminatti, L. J., and Guglielmo, L. G. A. (2016). The peak velocity derived from the Carminatti test is related to physical match performance in young soccer players. J. Sports Sci. 34, 2238-2245. doi: 10.1080/02640414.2016.1209307

Fernández, J., Schelling, X., Fernández, J., Ward, P., and Fernández, J. (2021). Decision support system applications for scheduling in professional team sport. The team's perspective. Front. Sports Act Living 3:678489. doi: 10.3389/fspor. 2021.678489

Fox, J. L., Conte, D., Stanton, R., McLean, B., and Scanlan, A. T. (2020). The application of accelerometer-derived moving averages to quantify peak demands in basketball. J. Strength Cond. Res. 35(Suppl. 2), S58-S63. doi: 10. 1519/jsc.0000000000003486

Fox, J. L., Stanton, R., and Scanlan, A. T. (2018). A comparison of training and competition demands in semiprofessional male basketball players. Res. Q. Exerc. Sport 89, 103-111. doi: 10.1080/02701367.2017.1410693

Freitas, T. T., Calleja-González, J., Alarcón, F., and Alcaraz, P. E. (2016). Acute Effects of two different resistance circuit training protocols on performance and perceived exertion in semiprofessional basketball players. J. Strength Cond. Res. 30, 407-414. doi: 10.1519/JSC.0000000000001123

Fuller, C. W., Ekstrand, J., Junge, A., Andersen, T. E., Bahr, R., Dvorak, J., et al. (2006). Consensus statement on injury definitions and data collection procedures in studies of football (soccer) injuries. Clin. J. Sport Med. 16, 97-106. doi: 10.1097/00042752-200603000-00003

Gabbett, T. J. (2016). The training-injury prevention paradox: should athletes be training smarter and harder? Br. J. Sports Med. 50, 273-280. doi: 10.1136/ bjsports-2015-095788

Gabbett, T. J., Kearney, S., Bisson, L. J., Collins, J., Sikka, R., Winder, N., et al. (2018a). Seven tips for developing and maintaining a high performance sports medicine team. Br. J. Sports Med. 52, 626-627. doi: 10.1136/bjsports-2017098426

Gabbett, T. J., Nielsen, R. O., Bertelsen, M. L., Bittencourt, N. F. N., Fonseca, S. T., Malone, S., et al. (2018b). In pursuit of the 'Unbreakable' athlete: what is the role of moderating factors and circular causation? Br. J. Sports Med. 53, 394-395. doi: 10.1136/bjsports-2018-099995

Gabbett, T. J., Polley, C., Dwyer, D. B., Kearney, S., and Corvo, A. (2014). Influence of field position and phase of play on the physical demands of match-play in professional rugby league forwards. J. Sci. Med. Sport 17, 556-561. doi: 10.1016/j.jsams.2013.08.002

García, J., Ibáñez, J. S., Gómez, A. M., and Sampaio, J. (2014). Basketball gamerelated statistics discriminating ACB league teams according to game location, game outcome and final score differences. Int. J. Perform. Anal. Sport 14, 443-452. doi: 10.1080/24748668.2014.11868733

Hägglund, M., Waldén, M., Bahr, R., and Ekstrand, J. (2005). Methods for epidemiological study of injuries to professional football players: developing the UEFA model. Br. J. Sports Med. 39, 340-346. doi: 10.1136/bjsm.2005.018267

Hopkins, W. G. (2002). A scale of magnitudes for effect statistics. New View Stat. 502:411. doi: 10.1590/1677-5449.180095

Hulin, B. T., Gabbett, T. J., Blanch, P., Chapman, P., Bailey, D., and Orchard, J. W. (2014). Spikes in acute workload are associated with increased injury risk in elite cricket fast bowlers. Br. J. Sports Med. 48, 708-712. doi: 10.1136/bjsports-2013092524

Hulin, B. T., Gabbett, T. J., Caputi, P., Lawson, D. W., and Sampson, J. A. (2016). Low chronic workload and the acute: chronic workload ratio are more predictive of injury than between-match recovery time: a two-season prospective cohort study in elite rugby league players. $\mathrm{Br}$. J. Sports Med. 50, 1008-1012. doi: 10.1136/bjsports-2015-095364 
Huyghe, T., Alcaraz, P. E., Calleja-González, J., and Bird, S. P. (2021). The underpinning factors of NBA game-play performance: a systematic review (2001-2020). Phys. Sportsmed. 1-29. doi: 10.1080/00913847.2021.1896957

Ireland, D., Dawson, B., Peeling, P., Lester, L., Heasman, J., and Rogalski, B. (2019). Do we train how we play? Investigating skill patterns in Australian football. Sci. Med. Football 3, 1-10. doi: 10.1080/24733938.2019.1595111

Issurin, V. (2008). Blok periodization vs training theory: a review. J. Sports Med. Phys. Fit. 48, 65-75.

Killen, N. M., Gabbett, T. J., and Jenkins, D. G. (2010). Training loads and incidence of injury during the preseason in professional rugby league players. J. Strength Cond. Res. 24, 2079-2084. doi: 10.1519/JSC.0b013e3181ddafff

Mallo, J. (2020). Team Sports Training. London: Routledge.

Malone, S., Hughes, B., Doran, D. A., Collins, K., and Gabbett, T. J. (2019). Can the workload-injury relationship be moderated by improved strength, speed and repeated-sprint qualities? J. Sci. Med. Sport 22, 29-34. doi: 10.1016/j.jsams. 2018.01.010

McLean, B. D., Strack, D., Russell, J., and Coutts, A. J. (2018). Quantifying physical demands in the national basketball association-challenges around developing best-practice models for athlete care and performance. Int. J. Sports Physiol. Perform. 14, 414-420. doi: 10.1123/ijspp.2018-0384

Naclerio, F., Faigenbaum, A. D., Larumbe-Zabala, E., Perez-Bibao, T., Kang, J., Ratamess, N. A., et al. (2013a). Effects of different resistance training volumes on strength and power in team sport athletes. J. Strength Cond. Res. 27, 1832-1840. doi: 10.1519/JSC.0b013e3182736d10

Naclerio, F., Moody, J., and Chapman, M. (2013b). Applied periodization: a methodological approach. J. Hum.Sport Exerc. 8(2 Suppl.), 350-366. doi: 10. 4100/jhse.2012.82.04

Nagorsky, E., and Wiemeyer, J. (2021). The structure of performance and training in esports. PLoS One 15:e237584. doi: 10.1371/journal.pone.0237584

Oosterwijk, P. R., van der Ark, L. A., and Sijtsma, K. (2016). "Numerical differences between guttman's reliability coefficients and the GLB," in Quantitative Psychology Research, Vol. 167, eds L. van der Ark, D. Bolt, W. C. Wang, J. Douglas, and M. Wiberg (Cham: Springer). doi: 10.1007/978-3-319-38759-8_ 12

Paulauskas, H., Kreivyte, R., Scanlan, A. T., Moreira, A., Siupsinskas, L., and Conte, D. (2019). Monitoring workload in elite female basketball players during the in-season phase: weekly fluctuations and effect of playing time. Int. J. Sports Physiol. Perform. 14, 941-948. doi: 10.1123/ijspp.2018-0741

Paulauskas, R., Masiulis, N., Vaquera, A., Figueira, B., and Sampaio, J. (2018). Basketball game-related statistics that discriminate between european players competing in the NBA and in the Euroleague. J. Hum. Kinet. 65, 225-233. doi: 10.2478/hukin-2018-0030

Peña, J., Moreno-Doutres, D., Borràs, X., Altarriba, A., Baiget, E., Caparrós, A., et al. (2017). Patellar tendinopathy in team sports. Strength Cond. J. 39, 20-30. doi: $10.1519 /$ ssc. 0000000000000303

Pojskic, H., Sisic, N., Separovic, V., and Sekulic, D. (2018). Association between conditioning capacities and shooting performance in professional basketball players: an analysis of stationary and dynamic shooting skills. J. Strength Cond. Res. 32, 1981-1992. doi: 10.1519/JSC.0000000000002100

Porta-Benache, J., Bosquet, L., and Blais, J. (2010). Validez de un encoder lineal comercial para calcular $1 \mathrm{rm}$ en press de banca a partir de la relación fuerzavelocidad. J. Sports Sci. Med. 9, 459-463.

Ramirez-Campillo, R., Garcia-Hermoso, A., Moran, J., Chaabene, H., Negra, Y., and Scanlan, A. T. (2020). The effects of plyometric jump training on physical fitness attributes in basketball players: a meta-analysis. J. Sport Health Sci. S2095-2546:30169. doi: 10.1016/j.jshs.2020.12.005

Reverter-Masía, J., Legaz-Arrese, A., Munguía-Izquierdo, D., Barbany, J. R., and Serrano-Ostáriz, E. (2009). A profile of the resistance training practices of elite Spanish club teams. J. Strength Cond. Res. 23, 1537-1547.

Rodas, G., Bove, T., Caparrós, T., Langohr, K., Medina, D., Hamilton, B., et al. (2019). Ankle sprain versus muscle strain injury in professional men's basketball: a 9-year prospective follow-up study. Orthop. J. Sports Med. 7:232596711984903. doi: 10.1177/2325967119849035

Rogalski, B., Dawson, B., Heasman, J., and Gabbett, T. J. (2013). Training and game loads and injury risk in elite Australian footballers. J. Sci. Med. Sport 16, 499-503. doi: 10.1016/j.jsams.2012.12.004

Roig Pull, M., and Ranson, C. (2007). Eccentric muscle actions: implications for injury prevention and rehabilitation. Phys. Ther. Sport 8, 88-97. doi: 10.1016/j. ptsp.2006.11.005
Sampaio, J., Lago, C., and Drinkwater, E. J. (2010). Explanations for the United States of America's dominance in basketball at the Beijing Olympic Games (2008). J. Sports Sci. 28, 147-152. doi: 10.1080/02640410903 380486

Santos, E. J., and Janeira, M. A. (2012). The effects of resistance training on explosive strength indicators in adolescent basketball players. J. Strength Cond. Res. 26, 2641-2647. doi: 10.1519/JSC.0b013e31823f8dd4

Šarabon, N., Smajla, D., Maffiuletti, N. A., and Bishop, C. (2020). Strength, jumping and change of direction speed asymmetries in soccer, basketball and tennis players. Symmetry 12:1664. doi: 10.3390/sym12101664

Schelling, X., and Torres-Ronda, L. (2013). Conditioning for basketball: quality and quantity of training. Strength Cond. J. 35, 89-94. doi: 10.1519/SSC. 0000000000000018

Schelling, X., and Torres-Ronda, L. (2016). An integrative approach to strength and neuromuscular power training for basketball. Strength Cond. J. 38, 72-80. doi: 10.1519/SSC.0000000000000219

Serpiello, F. R., McKenna, M. J., Stepto, N. K., Bishop, D. J., and Aughey, R. J. (2011). Performance and physiological responses to repeated-sprint exercise: a novel multiple-set approach. Eur. J. Appl. Physiol. 111, 669-678. doi: 10.1007/ s00421-010-1687-0

Simenz, C. J., Dugan, C. A., and Ebben, W. P. (2005). Strength and conditioning practices of National Basketball Association strength and conditioning coaches. J. Strength Cond. Res. 19, 495-504. doi: 10.1519/15264.1

Speranza, M. J. A., Gabbett, T. J., Johnston, R. D., and Sheppard, J. M. (2015). Muscular strength and power correlates of tackling ability in semiprofessional Rugby League players. J. Strength Cond. Res. 29, 2071-2078. doi: 10.1519/JSC. 000000000000897

Sperlich, P. F., Behringer, M., and Mester, J. (2016). The effects of resistance training interventions on vertical jump performance in basketball players: a meta-analysis. J. Sports Med. Phys. Fit. 56, 874-883.

Stone, W. J., and Steingard, P. M. (1993). Year-round conditioning for basketball. Clin. Sports Med. 12, 173-191.

Terrados, N., Mielgo-Ayuso, J., Delextrat, A., Ostojic, S. M., and Calleja-Gonzalez, J. (2019). Dietetic-nutritional, physical and physiological recovery methods post-competition in team sports. J. Sports Med. Phys. Fit. 59, 415-428. doi: 10.23736/S0022-4707.18.08169-0

Thorpe, R. T., Atkinson, G., Drust, B., and Gregson, W. (2017). Monitoring fatigue status in elite team-sport athletes: implications for practice. Int. J. Sports Physiol. Perform. 12(Suppl. 2), S227-S234. doi: 10.1123/ijspp.2016-0434

Usgu, S., Yakut, Y., and Kudas, S. (2020). Effects of functional training on performance in professional basketball players. Turk. J. Sports Med. 55, 321331. doi: 10.5152/tjsm.2020.193

Wen, N., Dalbo, V. J., Burgos, B., Pyne, D. B., and Scanlan, A. T. (2018). Power testing in basketball: current practice and future recommendations. J. Strength Cond. Res. 32, 2677-2691. doi: 10.1519/JSC.0000000000002459

Zhang, S., Gomez, M. Á, Yi, Q., Dong, R., Leicht, A., and Lorenzo, A. (2020). Modelling the relationship between match outcome and match performances during the 2019 FIBA Basketball World Cup: a quantile regression analysis. Int. J. Environ. Res. Public Health 17:5722. doi: 10.3390/ijerph17165722

Conflict of Interest: GR was employed by the FC Barcelona Medical Services.

The remaining authors declare that the research was conducted in the absence of any commercial or financial relationships that could be construed as a potential conflict of interest.

Publisher's Note: All claims expressed in this article are solely those of the authors and do not necessarily represent those of their affiliated organizations, or those of the publisher, the editors and the reviewers. Any product that may be evaluated in this article, or claim that may be made by its manufacturer, is not guaranteed or endorsed by the publisher.

Copyright @ 2022 Caparrós, Peña, Baiget, Borràs-Boix, Calleja-Gonzalez and Rodas. This is an open-access article distributed under the terms of the Creative Commons Attribution License (CC BY). The use, distribution or reproduction in other forums is permitted, provided the original author(s) and the copyright owner(s) are credited and that the original publication in this journal is cited, in accordance with accepted academic practice. No use, distribution or reproduction is permitted which does not comply with these terms. 